\title{
Quality of Cardiovascular Disease Care in Small Urban Practices
}

\author{
Donna Shelley, $M D, M P H^{1}$ \\ Batel Blechter, $M A^{1}$ \\ Nina Siman, MA, MSEd ${ }^{1}$ \\ Nan Jiang, $P b D^{1}$ \\ Charles Cleland, $\mathrm{PbD}^{2}$ \\ Gbenga Ogedegbe, MD, MS, MPH, \\ FACP ${ }^{1}$
}

Stepben Williams, $M D^{1}$

Winfred $W u, M D, M P H^{3}$

Erin Rogers, $P b D^{1}$

Carolyn Berry, $\mathrm{PbD}^{1,4}$

'School of Medicine, New York University, New York, New York

${ }^{2}$ Rory Meyers College of Nursing, New York University New York, New York

${ }^{3}$ Department of Health and Mental

Hygiene, Queens, New York

${ }^{4}$ School of Public Service, New York University, New York, New York New York

\section{Conflicts of interest: authors report none.}

\section{CORRESPONDING AUTHOR}

Donna Shelley, MD, MPH

New York University School of Medicine 227 E 30th St

New York, NY 10016

Donna.Shelley@nyumc.org

\begin{abstract}
PURPOSE We wanted to describe small, independent primary care practices' performance in meeting the Million Hearts ABCSs (aspirin use, blood pressure control, cholesterol management, and smoking screening and counseling), as well as on a composite measure that captured the extent to which multiple clinical targets are achieved for patients with a history of arteriosclerotic cardiovascular disease (ASCVD). We also explored relationships between practice characteristics and $A B C S$ measures.
\end{abstract}

METHODS We conducted a cross-sectional, bivariate analysis using baseline data from 134 practices in New York City. ABCS data were extracted from practices' electronic health records and aggregated to the site level. Practice characteristics were obtained from surveys of clinicians and staff at each practice.

RESULTS The proportion of at-risk patients meeting clinical goals for each of the ABCS measures was $73.0 \%$ for aspirin use, $69.6 \%$ for blood pressure, $66.7 \%$ for cholesterol management, and $74.2 \%$ screened for smoking and counseled. For patients with a history of ASCVD, only $49 \%$ were meeting all ABC (aspirin use, blood pressure control, cholesterol management) targets (ie, composite measure). Solo practices were more likely to meet clinical guidelines for aspirin (risk ratio $[R R]=1.17, P=.007)$ and composite $(R R=1.29, P=.011)$ than practices with multiple clinicians.

CONCLUSION Achieving targets for ABCS measures varied considerably across practices; however, small practices were meeting or exceeding Million Hearts goals (ie, $70 \%$ or greater). Practices were less likely to meet consistently clinical targets that apply to patients with a history of ASCVD risk factors. Greater emphasis is needed on providing support for small practices to address the complexity of managing patients with multiple risk factors for primary and secondary ASCVD.

Ann Fam Med 2018;16(Suppl_1):S21-S28. https://doi.org/10.1370/afm.2174.

\section{INTRODUCTION}

ardiovascular disease remains the number 1 cause of death in the United States. ${ }^{1}$ One-half of the US adult population has 1 or more preventable risk factors for arteriosclerotic cardiovascular disease (ASCVD), but less than one-half are meeting all of their clinical goals. ${ }^{2}$ Increasing the adoption of effective clinical preventive services that reduce ASCVD mortality, including treating hypertension and hyperlipidemia, would result in large improvements in population health. ${ }^{3}$

HealthyHearts New York City, 1 of 7 research cooperatives funded through the EvidenceNOW initiative, is studying the effectiveness of external practice facilitation to increase capacity among small, independent primary care practices to implement innovations in health care aimed at increasing adoption of the Million Hearts ABCS (aspirin use, blood pressure control, cholesterol management, and smoking cessation) guidelines. ${ }^{1,4}$ These guidelines include aspirin when indicated, blood pressure control, cholesterol management through guideline-recommended use of lipid-lowering medications, and both screening for tobacco use and offering smokers cessation interventions or counseling. 
There is a strong rationale for evaluating the impact of external support for practice transformation in small practices. Despite declines in the number of small practices in the United States, and market forces driving consolidation, small practices continue to provide care for a major proportion of the population. ${ }^{5,6} \mathrm{~A}$ recent survey of more than 10,000 family physicians found more than one-half worked in solo or very small practices (fewer than 5 clinicians). ${ }^{7}$

Although an important source of primary care, these practice settings are underrepresented in the quality improvement and practice transformation literature. Moreover, most practice improvement studies focus on a single risk factor, yet about $25 \%$ of adults in the United States have 2 or more concurrent chronic conditions. ${ }^{8}$ Based on strong evidence, guidelines for secondary prevention of ASCVD recommend comprehensive risk factor management that includes medication for lowering lipid levels and antihypertensive and antiplatelet agents. ${ }^{9,10}$ We are not aware, however, of any studies examining how well small practices that serve diverse populations are achieving goals across multiple risk factors in patients with a history of ASCVD.

HealthyHearts New York City provides an opportunity to fill gaps in knowledge about the performance of small practices on key quality indicators and factors that may influence patient care and clinical outcomes. We describe the baseline performance of small practices in meeting ABCS targets and a composite measure which captured the extent to which clinical targets are achieved across the measures of ABC (aspirin use, blood pressure control, cholesterol management) for patients with a history of ASCVD. We also explore associations between practice characteristics and $\mathrm{ABCS}$ measures.

\section{METHODS}

\section{Site Eligibility}

Study sites were primary care practices with $<10$ FTE clinicians in New York City that were members of the New York City Department of Health and Mental Hygiene's Primary Care Information Project (PCIP) practice network. PCIP is a bureau in the Division of Prevention and Primary Care and serves as New York City's Regional Extension Center., ${ }^{11,12}$ Site eligibility is described in more detail in a previous publication. ${ }^{13}$

\section{Study Design and Setting}

HealthyHearts New York City is using a steppedwedge, cluster randomized controlled trial design in which sites were randomized into 1 of 4 intervention waves to evaluate the effect of practice facilitation on ABCS measures in small independent practices in
New York City. Details about the study design are also described in the previously published protocol article. ${ }^{13}$

Of the 437 practices screened for eligibility, 291 were recruited through the PCIP network and randomized into 1 of the 4 waves. Thirty-four withdrew after randomization, leaving a total of 257 active practices. Participation in the study was voluntary. For this study, we included the 134 practices that submitted baseline survey responses on or before the cutoff date (February 15,2017$)$.

Of note, we have ABCS baseline data on all 257 practices. To explore the potential for selection bias, we conducted $t$ tests to compare the difference in the ABCS data among the 134 practices that completed a baseline questionnaire and the 123 practices without baseline survey data and found no significant differences.

\section{Study Instruments}

Baseline survey instruments included a practice questionnaire and a practice member questionnaire that were developed in collaboration with all 7 cooperatives and the external evaluation team. ${ }^{14}$ The practice questionnaire elicited information on practice characteristics (eg, size, ownership, staffing) and included the Change Process Capability Questionnaire (CPCQ). ${ }^{15-17}$ Either the lead clinician or office manager completed the practice questionnaire. The practice member questionnaire assessed organizational culture and additional measures of practice capacity (eg, adaptive reserve, burnout) and was completed at baseline by all clinicians and staff in all enrolled practices. ${ }^{18,19}$ Depending on their preferences, respondents completed mailed paper questionnaires or used REDCap, a Web-based format.

\section{Measures and Data Sources}

We analyzed baseline performance on the 4 individual ABCS measures and the composite measure. Data on practice and patient characteristics were obtained from the practice and practice member questionnaires, the PCIP practice database, and the Health Resources and Services Administration website. The survey items are in Supplemental Appendix 1, available at http://www. annfammed.org/content/16/Suppl_1/S21/supp1/DC1/.

\section{Dependent Variable}

ABCS measures were based on Million Hearts clinical quality measures and definitions that are approved by the National Quality Forum and were finalized through a collaborative process across the 7 cooperatives (Supplemental Appendix 2, available at http:// www.annfammed.org/content/16/Suppl_1/S21/suppl/ DC1/). ${ }^{20,21}$ The individual measures were defined as the proportion of at-risk patients who reached 
clinical goals for each of the 4 guidelines: aspirin use when indicated $(\mathrm{A})$, blood pressure control $(\mathrm{B})$, cholesterol management $(\mathrm{C})$, and screened for tobacco use and offered cessation intervention if identified as a tobacco user (S). For example, the aspirin measure was defined as the proportion of patients aged 18 years and older with ASCVD who had documented use of aspirin or other antithrombotic. Baseline data included all patients that met criteria for at least 1 of the ABCS measures and had a visit during the 1-year period before the start of the intervention (January 1, 2015-December 31, 2015). A composite measure assessed the proportion of patients with a history of ASCVD who met treatment targets for 3 of the 4 Million Hearts outcomes (ABC). We were unable to include the smoking measure because of limitations associated with our measure reporting system.

The ABCS data were extracted through electronic queries executed directly against the practice electronic health records. A trend analysis during the 12-month baseline period indicated no significant changes in ABCS measures with time.

\section{Independent Variables}

For practice characteristics, survey data assessed number of clinicians (solo vs 2 or more), practice ownership (independent vs other), accountable care organization (ACO) status (part of ACO vs other), and full-timeequivalent of supporting staff (ie, medical assistant, registered nurse, office manager, etc). We used the PCIP practice database to obtain data on patientcentered medical home (PCMH) status and patient panel size, and the Health Resources and Services Administration website to obtain the practices' medically underserved area designation. ${ }^{21}$

For patient characteristics, insurance status was obtained from the practice survey questionnaire and defined as the percentage of patients in a site that were covered by a Medicaid payer (including Medicaid-only payers and dual Medicaid and Medicare payers). We obtained data on patient race and ethnicity using the PCIP practice database.

Organizational capacity measures included adaptive reserve, ${ }^{18}$ a measure of practices' ability to make and sustain change $_{i}$ the CPCQ ${ }_{1}^{15}$ a measure of practices' strategies for quality improvement; and burnout. ${ }^{19}$ All measures were assessed by the lead clinician. Both the CPCQ and adaptive reserve included 14 items. Questions were answered on a 5-point Likert scale ranging from "strongly disagree" to "strongly agree." Consistent with the literature, we converted the score for each item to a $0-1$ scale and then calculated the mean by summing all values for nonmissing items and dividing by the number of nonmissing items. ${ }^{18} \mathrm{~A}$ larger value indicated a higher level of adaptive reserve, and for the CPCQ, greater adoption of the range of quality improvement strategies assessed.

To assess burnout, clinicians checked 1 of 5 statements that best described their feelings about the situation at work (Supplemental Appendix 1). A dichotomous variable for the analysis compared not burned out (for those who chose "I enjoy my work," or "I have no symptoms of burnout"), and burned out for those who checked 1 of the last 3 options (eg, "I am definitely burning out and have one or more symptoms of burnout, such as physical and emotional exhaustion").

\section{Statistical Analysis}

All analysis was performed using the R program. ${ }^{22}$ Descriptive statistics summarized baseline practice characteristics, patient characteristics, and organizational capacity. $\beta$ Regression ${ }^{23}$ with pairwise deletion of missing data was used to estimate bivariate associations between independent variables and ABCS measures. To address the number of bivariate analyses conducted and control the type I error rate, we adjusted $P$ values using the Holm method. ${ }^{24}$ Values of ABCS that were exactly 0 or 1 were recoded using the formula suggested by Smithson and Verkuilen. ${ }^{25}$ In the precision portion of the $\beta$ regression model, the $\log$ transformed number of patients considered for the ABCS measure was included as the sole explanatory variable. All significance tests were 2-tailed.

\section{RESULTS}

\section{ABCS Individual and $A B C$ Composite Measures}

Figure 1 shows the $\mathrm{ABCS}$ and $\mathrm{ABC}$ composite measures across the 134 practices. On average, $73.0 \%(\mathrm{SD}=17.3 \%)$ of eligible patients were receiving aspirin, $69.6 \%$ $(\mathrm{SD}=12.9 \%)$ achieved recommended blood pressure control, $66.7 \%(\mathrm{SD}=13.8 \%)$ met the target for cholesterol medication management, and $74.2 \%(\mathrm{SD}=18.8 \%)$ of patients with a visit during the baseline period were screened for tobacco use and, if identified as a smoker, offered a cessation intervention or counseling. Among those patients with a history of ASCVD, however, only $49 \%(\mathrm{SD}=17.8 \%)$ met all the $\mathrm{ABC}$ recommended treatment targets (ie, the composite measure).

\section{Practice Characteristics}

Table 1 shows the characteristics of the 134 practices. Most (73.2\%) practices were solo-clinician practices, $91.7 \%$ were independently owned by clinicians, and $11.4 \%$ of lead clinicians reported experiencing symptoms of burnout. On average, practices reported that less than $20 \%$ of patients were non-Hispanic white, and $43.3 \%$ were covered by Medicaid. 


\section{Association Between}

Characteristics of Small

Practices and ABCS Measures

Table 2 shows the bivariate analyses of the associations between the independent variables and the ABCS measures. Solo-clinician practices were more likely than practices with more than 1 clinician to meet the clinical guidelines for aspirin treatment (risk ratio $[\mathrm{RR}]=1.17,95 \% \mathrm{CI}, 1.08$ $1.25, P=.007)$ and the ABC composite measure $(\mathrm{RR}=1.29,95 \%$ CI, 1.12-1.47, $P=.011)$. Because few bivariate associations were significant, we did not undertake multivariate analyses.

\section{DISCUSSION}

Small practices in New York City, on average, were meeting or were very close to meeting Million Hearts individual clinical goals for the ABCSs (ie, $70 \%$ or greater) before initiation of the practice facilitation intervention. Comparison with 2014 national and New York State data further suggest that these small practices are comparable in performance to the full spectrum of primary care practices. ${ }^{20}$

Despite this overall good news, it is noteworthy that considerable variability exists among practices in the ABCS measures, meaning that many small practices fall below target levels on each of the measures. For example, only $41 \%$ of practices met the $70 \%$ target for the cholesterol measure. Further, the average rate of compliance with the composite measure was only $49 \%$, indicating there is ample room for improvement in managing multiple risk factors for patients with a history of ASCVD. Other studies have found comparably low rates of simultaneous control among patients with concurrent risk factors for cardiovascular disease. ${ }^{26}$ Managing multiple risk factors is a complex process, and literature on effective interventions to address this quality gap is scarce. Because
Figure 1. Proportion of patients who meet the treatment target of the ABCS clinic guidelines among small, independent, primary care practices in New York City $(\mathrm{N}=134)$.
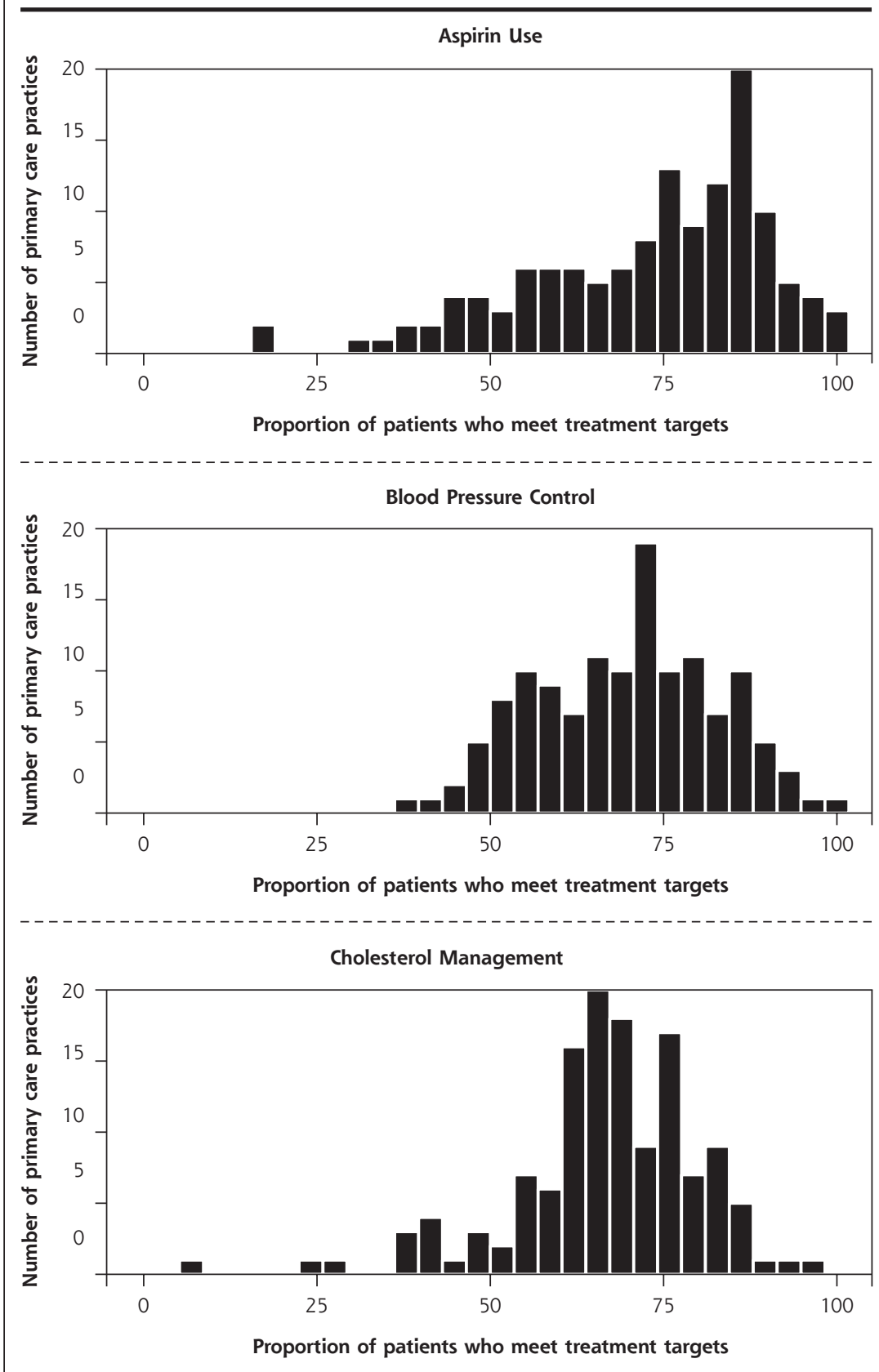

$A B C=$ aspirin use, blood pressure control, cholesterol management; $A B C S=$ aspirin use, blood pressure control, cholesterol management, and smoking screening and counseling.

research indicates that reductions in both primary and secondary ASCVD-related deaths are highly correlated with the number of risk factors controlled, developing strategies to support small practices to improve multiple risk factors simultaneously should be a high priority. ${ }^{10,27}$ HealthyHearts New York City's focus on improving outcomes across all of the ABCS measures 


\section{Figure 1. Proportion of patients who meet the treatment target of the $A B C S$ clinic guidelines among small, independent, primary care practices in New York City $(\mathrm{N}=134)$. (continued)}
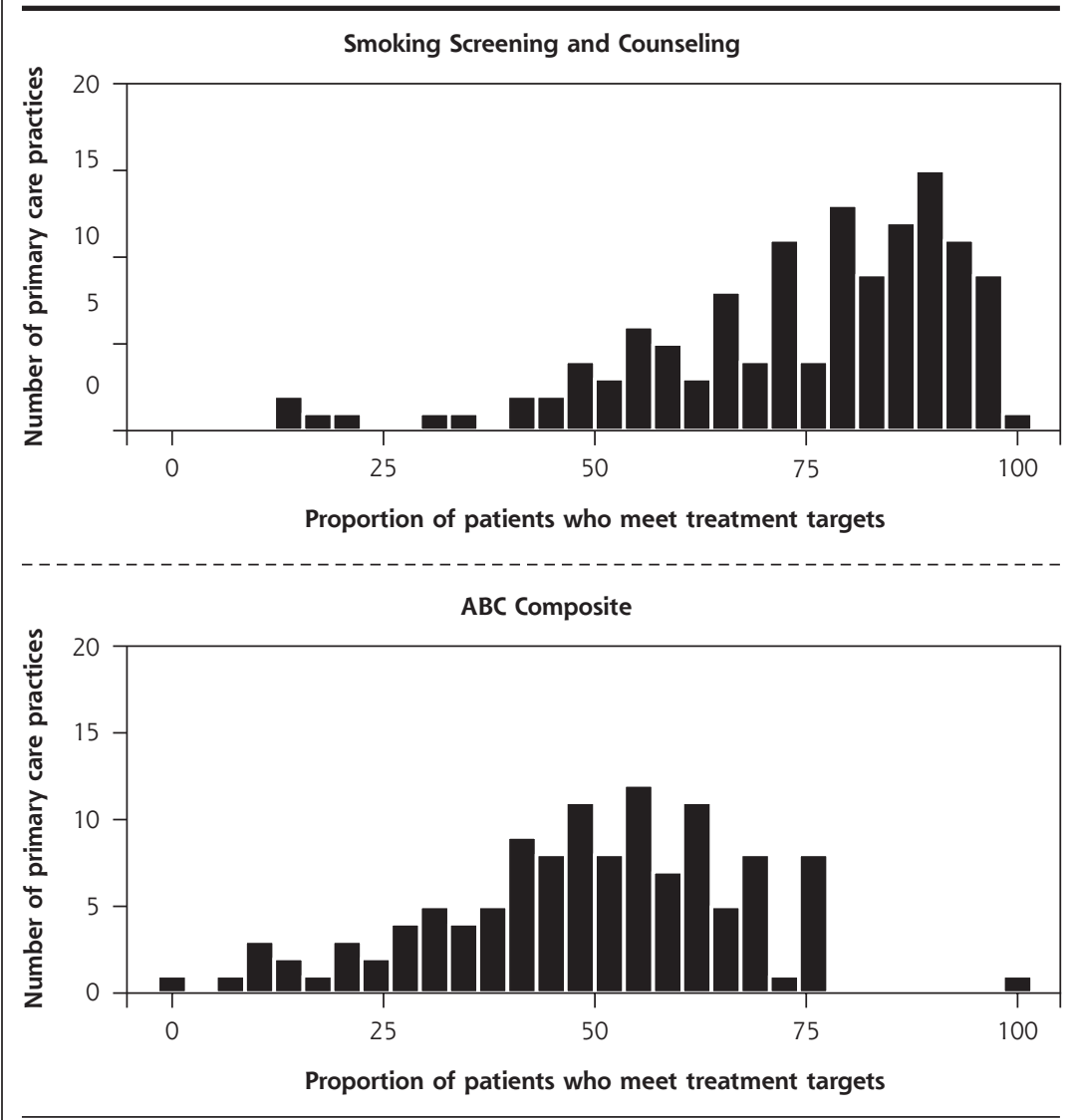

$A B C=$ aspirin use, blood pressure control, cholesterol management; $A B C S=$ aspirin use, blood pressure control, cholesterol management, and smoking screening and counseling crude measure of PCMH status that does not capture the extent to which the multiple components of PCMH are implemented. ${ }^{34}$ Similarly, measures of organizational capacity (ie, adaptive reserve and the CPCQ) were not associated with baseline ABCS measures. There is some evidence that adopting a larger number of PCMH components is associated with improvement in quality of care scores for chronic disease management. ${ }^{35,36} \mathrm{We}$ are not aware of any literature to date, however, that has reported an association between change capacity and ABCS outcomes. Further study is needed to identify practice characteristics that are associated with improvements in care processes and patient outcomes. Additional research is also needed to better elucidate the value of offering practice facilitation and other types of support build small practice capacity to implement evidencebased changes in health care delivery. ${ }^{37}$

The overall lack of consistent associations between baseline characteristics of the study sites and ABCS measures may sug- offers an opportunity to explore the impact of external facilitation on helping small practices achieve clinical targets for these high-risk patients. ${ }^{13}$

We found no consistent pattern of relationships among most of the practice, patient, and organizational characteristics and the ABCS measures, despite substantial variability in these measures. The only practice characteristic associated with ABCS measures was number of clinicians; solo practitioners outperformed practices with multiple clinicians. Recent studies and commentaries suggest that small practices struggle more than larger practices to provide optimal care. ${ }^{28-30}$ The results from this baseline assessment, however, belie that perception and suggest that with the type of ongoing support provided by PCIP and participation in similar programs that offer shared resources, such as ACOs and independent practice associations, very small and solo practices can meet targets for quality metrics. ${ }^{31-33}$

The lack of association between PCMH recognition and ABCS measures may reflect the use of a gest that very small practices require the application of different organizational frameworks or lenses to identify and understand what factors are associated with practice improvement. We might need to look to the broader literature on small businesses and the differences between small and large businesses in terms of decision-making power, communication, and the use of more informal approaches to practice change. ${ }^{38,39}$ In solo clinician sites, $\mathrm{ABCS}$ performance essentially reflects the performance of the individual clinician and may be better studied by measuring individual-level constructs that were not included in our questionnaires, such as clinician motivation, beliefs, skills, and social support and influences commonly found to be associated with clinician behavior. ${ }^{40}$ Small practices continue to provide health care for a large proportion of Americans. This important role warrants further investments in research to identify care structures and processes in these settings that are associated with better care and better clinical outcomes. 
Table 1. Characteristics of Small Independent Primary Care Practices $(\mathrm{N}=134)$

\begin{tabular}{|c|c|c|c|}
\hline Characteristic & Value & Characteristic & Value \\
\hline Practice & & \multicolumn{2}{|l|}{ Patient } \\
\hline \multicolumn{2}{|l|}{ Clinicians } & $\begin{array}{l}\text { Non-Hispanic white } \\
\text { patient, mean (SD), \% }\end{array}$ & $19.3(26.8)$ \\
\hline $\begin{array}{l}\text { Solo clinician, No. (\%) } \\
\geq 2 \text { Clinicians, No. (\%) }\end{array}$ & $\begin{array}{l}93(73.2) \\
34(26.8)\end{array}$ & $\begin{array}{l}\text { Medicaid payer, mean } \\
\text { (SD), \% }\end{array}$ & $43.3(27.5)$ \\
\hline $\begin{array}{l}\text { Practice ownership } \\
\text { Independent, No. (\%) } \\
\text { Other, No. (\%) }\end{array}$ & $\begin{array}{c}122(91.7) \\
11(8.3)\end{array}$ & $\begin{array}{l}\text { Adaptive reserve, mean } \\
\text { (SD), No. }\end{array}$ & $0.8(0.2)$ \\
\hline $\begin{array}{l}\text { ACO status } \\
\text { Part of ACO, No. (\%) } \\
\text { Other, No. (\%) }\end{array}$ & $\begin{array}{l}57(42.5) \\
77(57.5)\end{array}$ & $\begin{array}{l}\text { CPCQd, mean (SD), No. } \\
\text { Burnout of lead clinician, } \\
\text { No. (\%) }\end{array}$ & $0.8(0.2)$ \\
\hline \multicolumn{2}{|l|}{ MUA designation ${ }^{a}$} & Yes & $12(11.4)$ \\
\hline Yes, No. (\%) & $56(41.8)$ & \multirow[t]{7}{*}{ No } & \multirow[t]{2}{*}{$93(88.6)$} \\
\hline No, No. (\%) & $78(58.2)$ & & \\
\hline \multicolumn{3}{|l|}{ PCMH recognition } & \\
\hline Yes, No. (\%) & $60(44.8)$ & & \\
\hline No, No. $(\%)$ & $74(55.2)$ & & \\
\hline $\begin{array}{l}\text { Full-time equivalent of support- } \\
\text { ing staff, mean (SD), No. }\end{array}$ & $4.8(5.9)$ & & \\
\hline $\begin{array}{l}\text { Patient panel size, mean (SD), } \\
\text { No. }\end{array}$ & $\begin{array}{c}1,969.2 \\
(2,264.6)\end{array}$ & & \\
\hline \multicolumn{4}{|c|}{$\begin{array}{l}\mathrm{ACO}=\text { accountable care organization; } \mathrm{CPCQ}=\text { Change Process Capability Questionnaire; } \mathrm{MUA}=\text { medically under- } \\
\text { served area; } \mathrm{PCMH}=\text { patient-centered medical home. }\end{array}$} \\
\hline \multicolumn{4}{|c|}{$\begin{array}{l}\text { Note: Among } 134 \text { small independent primary care practices, } 113 \text { reported full-time equivalent of supporting } \\
\text { staff; } 120 \text { provided data about patient panel size and the percentage of white patients; } 105 \text { reported the per- } \\
\text { centage of Medicaid payers among their patients; and } 112 \text { completed data on adaptive reserve. }\end{array}$} \\
\hline a Data extracted from Health Resource & and Services Ad & ration website. & \\
\hline
\end{tabular}

\section{Limitations}

Our main limitation for this study is that the practices included in this study were not randomly selected ${ }_{i}$ however, the large sample includes practices from all 5 city boroughs (aka counties) with similarly diverse patient populations. Additional imitations include the need to exclude 123 practices from the analysis because we did not receive their baseline survey data by the cutoff date for the study. As noted, further analysis found no significant difference in baseline ABCS measures between the 134 included practices and the 123 excluded practices. Finally, the $\beta$ regression model tested 60 hypotheses, and we found 2 significant results (Table 2).

Conventional wisdom gleaned from the study of large practices, which constitutes the vast bulk of the literature on primary care practice, may provide only limited value in develop-

Table 2. Bivariate Analysis of the Factors Associated With the Outcomes of ABCS and Composite Measures

\begin{tabular}{|c|c|c|c|c|c|c|}
\hline \multirow[b]{2}{*}{ Characteristic } & \multicolumn{2}{|c|}{ Aspirin Use } & \multicolumn{2}{|c|}{ Blood Pressure Control } & \multicolumn{2}{|c|}{$\begin{array}{c}\text { Cholesterol } \\
\text { Management }\end{array}$} \\
\hline & RR $(95 \% \mathrm{Cl})$ & $P$ Value & RR $(95 \% \mathrm{Cl})$ & $P$ Value & RR $(95 \% \mathrm{Cl})$ & $P$ Value \\
\hline \multicolumn{7}{|l|}{ Practice } \\
\hline Number of clinicians (solo) & $1.17(1.08-1.25)$ & .007 & $1.02(0.96-1.09)$ & $>.999$ & $1.07(0.98-1.14)$ & $>.999$ \\
\hline Practice ownership (Independent) & $0.99(0.84-1.12)$ & $>.999$ & $0.96(0.84-1.06)$ & $>.999$ & $0.98(0.85-1.09)$ & $>.999$ \\
\hline ACO status (yes) & $1.05(0.97-1.12)$ & $>.999$ & $0.99(0.93-1.05)$ & $>.999$ & $0.97(0.90-1.04)$ & $>.999$ \\
\hline MUA designation ${ }^{a}$ (yes) & $1.05(0.97-1.12)$ & $>.999$ & $0.97(0.91-1.03)$ & $>.999$ & $0.96(0.89-1.03)$ & $>.999$ \\
\hline PCMH recognition (yes) & $1.01(0.93-1.08)$ & $>.999$ & $1.03(0.97-1.09)$ & $>.999$ & $1.02(0.95-1.09)$ & $>.999$ \\
\hline $\begin{array}{l}\text { Full-time equivalent of support- } \\
\text { ing staff }\end{array}$ & $1.01(0.95-1.06)$ & $>.999$ & $0.98(0.94-1.02)$ & $>.999$ & $1.02(0.97-1.06)$ & $>.999$ \\
\hline Patient panel size & $0.99(0.95-1.02)$ & $>.999$ & $0.98(0.96-1.00)$ & $>.999$ & $0.99(0.96-1.03)$ & $>.999$ \\
\hline \multicolumn{7}{|l|}{ Patient } \\
\hline Non-Hispanic white patient & $0.82(0.66-0.97)$ & .145 & $1.13(1.01-1.23)$ & .416 & $1.01(0.88-1.12)$ & $>.999$ \\
\hline Medicaid payer & $1.08(0.90-1.21)$ & $>.999$ & $0.94(0.81-1.06)$ & $>.999$ & $1.06(0.90-1.19)$ & $>.999$ \\
\hline \multicolumn{7}{|l|}{ Organizational capacity } \\
\hline Adaptive reserve & $0.81(0.58-0.99)$ & .330 & $1.05(0.86-1.20)$ & $>.999$ & $0.83(0.62-1.00)$ & .588 \\
\hline CPCQ & $0.90(0.64-1.09)$ & $>.999$ & $1.13(0.93-1.30)$ & $>.999$ & $0.89(0.68-1.06)$ & $>.999$ \\
\hline Burnout of lead clinician (yes) & $1.05(0.91-1.16)$ & $>.999$ & $1.04(0.93-1.13)$ & $>.999$ & $1.04(0.91-1.15)$ & $>.999$ \\
\hline \multicolumn{7}{|c|}{$\begin{array}{l}A B C=\text { aspirin use, blood pressure control, and cholesterol management; } A B C S=\text { aspirin use, blood pressure control, cholesterol management, smoking screening } \\
\text { and counseling; } A C O=\text { accountable care organization; } C P C Q=\text { Change Process Capability Questionnaire; } M U A=\text { medically underserved area; } P C M H=\text { patient-centered } \\
\text { medical home; } R R=\text { risk ratio. }\end{array}$} \\
\hline \multicolumn{7}{|c|}{ Note: $P$ values were adjusted for multiple testing using the Holm method. ${ }^{24}$} \\
\hline a Data extracted from the Health Resource & Id Services Administrat & n website. & & & & \\
\hline
\end{tabular}


ing, implementing, and evaluating interventions that will meaningfully improve the care provided in small practices. HealthyHearts New York City will provide much needed insight into the types of support small, independent practices need to achieve optimal patient health outcomes.

To read or post commentaries in response to this article, see it online at http://www.AnnFamMed.org/content/16/Suppl_1/S21.

Key words: cardiovascular disease; practice facilitation; small primary care practices; quality improvement

Submitted June 13, 2017; submitted, revised, October 6, 2017; accepted October 11, 2017.

Funding support: This project was supported by the Agency for Healthcare Research and Quality (AHRQ) through contract No. HHSA29020120009I, and grant No. R18 HS023922.

Disclaimer: This work represents the opinions of the authors and should not be interpreted as official positions of the Agency for Healthcare Research and Quality or the US Department of Health and Human Services.

Previous presentation: This study was presented in part at the New York State Population Health Summit; December 12, 2016; New York, New York.

Supplementary materials: Available at http://www.AnnFamMed. org/content/16/Suppl_1/S21/suppl/DC1/.

Smoking Screening and Counseling

RR $(95 \% \mathrm{Cl}) \quad P$ Value $\quad$ RR $(95 \% \mathrm{Cl}) \quad P$ Value

$\begin{array}{lllr}1.02(0.93-1.10) & >.999 & 1.29(1.12-1.47) & .011 \\ 1.03(0.88-1.15) & >.999 & 0.92(0.70-1.13) & >.999 \\ 1.04(0.96-1.11) & >.999 & 1.11(0.97-1.26) & >.999 \\ 1.03(0.95-1.10) & >.999 & 1.01(0.88-1.15) & >.999 \\ 1.06(0.98-1.13) & >.999 & 1.07(0.93-1.21) & >.999 \\ 1.02(0.96-1.07) & >.999 & 1.00(0.92-1.08) & >.999 \\ & & & \\ 1.02(0.95-1.08) & >.999 & 0.96(0.91-1.00) & .704 \\ & & & \\ 0.79(0.61-0.95) & 0.098 & 0.95(.68-1.24) & >.999 \\ 1.17(1.01-1.28) & 0.434 & 1.09(0.80-1.38) & >.999 \\ & & & \\ 0.90(0.65-1.07) & >.999 & 0.87(0.56-1.19) & >.999 \\ 1.21(0.93-1.40 & >.999 & 1.01(0.66-1.37) & >.999 \\ 1.07(0.93-1.17) & >.999 & 1.13(0.91-1.35) & >.999\end{array}$

\section{References}

1. Centers for Disease Control and Prevention (CDC). Million hearts: strategies to reduce the prevalence of leading cardiovascular disease risk factors-United States, 2011. MMWR Morb Mortal W/kly Rep. 2011;60(36):1248-1251.

2. Yang Q, Cogswell ME, Flanders WD, et al. Trends in cardiovascular health metrics and associations with all-cause and CVD mortality among US adults. JAMA. 2012;307(12):1273-1283.

3. Farley TA, Dalal MA, Mostashari F, Frieden TR. Deaths preventable in the U.S. by improvements in use of clinical preventive services. Am J Prev Med. 2010;38(6):600-609.

4. U.S. Department of Health \& Human Services. EvidenceNOW: Advancing Heart Health in Primary Care. https://www.ahrq.gov/ evidencenow/index.html.

5. Hing E, Schappert SM. Generalist and specialty physicians: supply and access, 2009-2010. NCHS Data Brief. 2012;105(105):1-8. Accessed 2009

6. Hing $E$, Uddin S. Visits to primary care delivery sites: United States, 2008. NCHS Data Brief. 2010;47(47):1-8.

7. Liaw WR, Jetty A, Petterson SM, Peterson LE, Bazemore AW. Solo and small practices: A vital, diverse part of primary care. Ann Fam Med. 2016;14(1):8-15.

8. Parekh AK, Barton MB. The challenge of multiple comorbidity for the US health care system. JAMA. 2010;303(13):1303-1304.

9. Pflieger M, Winslow BT, Mills K, Dauber IM. Medical management of stable coronary artery disease. Am Fam Physician. 2011;83(7):819-826.

10. Smith SC Jr, Benjamin EJ, Bonow RO, et al. AHA/ACCF secondary prevention and risk reduction therapy for patients with coronary and other atherosclerotic vascular disease: 2011 update: a guideline from the American Heart Association and American College of Cardiology Foundation endorsed by the World Heart Federation and the Preventive Cardiovascular Nurses Association. J Am Coll Cardiol. 2011;58(23):2432-2446.

11. City of New York. Primary Care Information Project. http://www1. nyc.gov/site/doh/providers/electronic-records.page.

12. Buck MD, Anane S, Taverna J, Amirfar S, Stubbs-Dame R, Singer J. The Hub Population Health System: distributed ad hoc queries and alerts. J Am Med Inform Assoc. 2012;19(e1):e46-e50.

13. Shelley DR, Ogedegbe $G$, Anane $S$, et al. Testing the use of practice facilitation in a cluster randomized stepped-wedge design trial to improve adherence to cardiovascular disease prevention guidelines: HealthyHearts NYC. Implement Sci. 2016;11(1):88.

14. Cohen DJ, Balasubramanian BA, Gordon L, et al. A national evaluation of a dissemination and implementation initiative to enhance primary care practice capacity and improve cardiovascular disease care: the ESCALATES study protocol. Implement Sci. 2016;11(1):86.

15. Solberg LI, Asche SE, Margolis KL, Whitebird RR. Measuring an organization's ability to manage change: the change process capability questionnaire and its use for improving depression care. Am J Med Qual. 2008;23(3):193-200.

16. Cohen DJ, Balasubramanian BA, Isaacson NF, Clark EC, Etz RS, Crabtree BF. Coordination of health behavior counseling in primary care. Ann Fam Med. 2011;9(5):406-415.

17. Balasubramanian BA, Cohen DJ, Clark EC, et al. Practice-level approaches for behavioral counseling and patient health behaviors. Am J Prev Med. 2008;35(5)(Suppl):S407-S413.

18. Jaén CR, Crabtree BF, Palmer RF, et al. Methods for evaluating practice change toward a patient-centered medical home. Ann Fam Med. 2010;8(Suppl 1):S9-S20.

19. Linzer M, Manwell LB, Williams ES, et al; MEMO (Minimizing Error, Maximizing Outcome) Investigators. Working conditions in primary care: physician reactions and care quality. Ann Intern Med. 2009; 151(1):28-36, W6-9. 
20. Million Hearts. Clinical Quality Measures. https://millionhearts.hhs. gov/files/MH_CQM.pdf.

21. National Quality Forum (NQF). Measures, Reports $\&$ Tools. http:// www.qualityforum.org/Measures_Reports_Tools.aspx.

22. The R Foundation. R: A language and environment for statistical computing. 2017. https://www.R-project.org/.

23. Cribari-Neto F, Zeileis A. Beta regression in R. J Stat Softw. 2010; 34(2):1-24.

24. Holm S. A simple sequentially rejective multiple test procedure. Scand J Stat. 1979;6(2):65-70.

25. Smithson M, Verkuilen J. A better lemon squeezer? Maximumlikelihood regression with beta-distributed dependent variables. Psychol Methods. 2006;11(1):54-71.

26. Schroeder EB, Hanratty R, Beaty BL, Bayliss EA, Havranek EP, Steiner JF. Simultaneous control of diabetes mellitus, hypertension, and hyperlipidemia in 2 health systems. Circ Cardiovasc Qual Outcomes. 2012;5(5):645-653.

27. Bittner V, Bertolet M, Barraza Felix R, et al; BARI 2D Study Group. Comprehensive Cardiovascular Risk Factor Control Improves Survival: The BARI 2D Trial. J Am Coll Cardiol. 2015;66(7):765-773.

28. Bodenheimer T, Pham HH. Primary care: current problems and proposed solutions. Health Aff (Millwood). 2010;29(5):799-805.

29. Rittenhouse DR, Casalino LP, Shortell SM, et al. Small and mediumsize physician practices use few patient-centered medical home processes. Health Aff (Millwood). 2011;30(8):1575-1584.

30. Nutting PA, Crabtree BF, McDaniel RR. Small primary care practices face four hurdles-including a physician-centric mind-set-in becoming medical homes. Health Aff (Millwood). 2012;31(11): 2417-2422.

31. Casalino LP, Wu FM, Ryan AM, et al. Independent practice associations and physician-hospital organizations can improve care management for smaller practices. Health Aff (Millwood). 2013;32(8): 1376-1382.
32. Wang JJ, Winther $\mathrm{CH}$, Cha J, et al. Patient-centered medical home and quality measurement in small practices. Am J Manag Care. 2014; 20(6):481-489.

33. Shields MC, Patel PH, Manning M, Sacks L. A model for integrating independent physicians into accountable care organizations. Health Aff (Millwood). 2011;30(1):161-172.

34. National Committee for Quality Assurance (NCQA). Patient-Centered Medical Home (PCMH) Recognition. http://www.ncqa.org/programs/ recognition/practices/patient-centered-medical-home-pcmh.

35. Jaén $C R$, Ferrer RL, Miller WL, et al. Patient outcomes at 26 months in the patient-centered medical home National Demonstration Project. Ann Fam Med. 2010;8(Suppl 1):S57-67;S92.

36. Nutting PA, Crabtree BF, Stewart EE, et al. Effect of facilitation on practice outcomes in the National Demonstration Project model of the patient-centered medical home. Ann Fam Med. 2010;8(Suppl 1):S33-44; S92.

37. Berry CA, Mijanovich T, Albert S, et al. Patient-centered medical home among small urban practices serving low-income and disadvantaged patients. Ann Fam Med. 2013;11(Suppl 1):S82-S89.

38. Harrison DA, Mykytyn PP Jr, Riemenschneider CK. Executive decisions about adoption of information technology in small businesses and theory and empirical tests. Inf Syst Res. 1997;8(2):171-195.

39. Dandridge TC. Children are not "Little grown-ups": Small business needs its own organizational theory. J Small Bus Manag. 1979;17(2): 53-57.

40. Francis JJ, O'Connor D, Curran J. Theories of behaviour change synthesised into a set of theoretical groupings: introducing a thematic series on the theoretical domains framework. Implement Sci. 2012;7:35. 